\title{
SAPHO Syndrome Diagnosis and Treatment: Report of Five Cases and Review of the Literature
}

\author{
Ch. Matzaroglou ${ }^{1}$, D. Velissaris ${ }^{2}$, A. Karageorgos ${ }^{1}$, M. Marangos ${ }^{3}$, E. Panagiotopoulos ${ }^{1}$ and \\ M. Karanikolas ${ }^{*}, 2$ \\ ${ }^{I}$ Department of Orthopaedic Surgery, University of Patras Medical School, Patras, Greece \\ ${ }^{2}$ Department of Anaesthesiology and Intensive Care Medicine, University of Patras Medical School, Patras, Greece \\ ${ }^{3}$ Department of Internal Medicine, University of Patras Medical School, Patras, Greece
}

\begin{abstract}
Background: The term "SAPHO (Synovitis, Acne, Pustulosis, Hyperostosis and Osteitis) syndrome" includes a variety of musculoskeletal disorders associated with skin conditions; Osteitis is the most prominent skeletal lesion, whereas palmoplantar pustulosis and acne are the main skin lesions. Diagnosing SAPHO syndrome is difficult, because this syndrome is often confused with suppurative osteomyelitis, which has similar clinical and pathologic findings. SAPHO diagnosis is even more difficult when atypical sites are involved and there are no skin lesions.

Patients and Methods: This case series presents five patients ( 3 women, 2 men), ages 27 to 44 years, who came to the Orthopaedic Department outpatient clinic for evaluation of pain in the humerus, clavicle, sacro-iliac joints, and/or distal radius, and were diagnosed with SAPHO syndrome. Clinical and radiologic findings, treatment and outcome data, with up to 4 years of follow-up are presented. An extensive discussion of the clinical presentation, published literature, treatment options and outcome of SAPHO syndrome is also included.

Results: Once the diagnosis of SAPHO syndrome was established, treatment with antibiotics (clindamycin) and non steroid anti-inflammatory drugs (lornoxicam) was remarkably effective. All patients did well and remained symptom free for up to four years, after a 3-8 month course of treatment.

Interpretation: SAPHO syndrome should be included in the differential diagnosis when evaluating patients with lytic, sclerotic, or hyperostotic bone lesions and pain. Prompt SAPHO syndrome recognition, followed by appropriate therapy with antibiotics and NSAIDs can produce rapid symptom resolution, while avoiding unnecessary procedures and longterm antibiotic therapy.
\end{abstract}

Keywords: SAPHO, synovitis, acne, pustulosis, hyperostosis, osteitis, pain, lornoxicam, clindamycin.

\section{INTRODUCTION}

SAPHO (synovitis, acne, pustulosis, hyperostosis and osteitis) syndrome [1] is characterized by osteoarticular and dermatological manifestations. Chamot and co-workers first described in 1987 [2] "le syndrome acne pustulose hyperostose osteite" and introduced the acronym SAPHO, to designate the constellation of these five frequently combined disorders. The syndrome can occur at any age but usually appears between childhood and middle age and follows a prolonged relapsing and remitting course [3].

Hyperostosis and osteitis are the most prominent SAPHO syndrome findings [4,5]. Hyperostosis appears radiologically as osteosclerosis, with cortical thickening, narrowing of the medullary canal, and external surface of the bone appearing expanded, indistinct and irregular. Osteitis refers to bone inflammation that appears histopathologically as a sterile inflammatory infiltrate. Bacterial cultures are usually negative [3], but low virulence microbial agents, such as

*Address correspondence to this author at the Department of Anaesthesiology and Intensive Care Medicine, University of Patras Medical School, Patras, Greece; E-mail: kmenelaos@yahoo.com
Propionibacterium acnes ( $P$ acnes) have been isolated in deep bone biopsy specimens in a few cases [6-11], and Staphylococcus Aureus (S. Aureus) has been isolated from a plantar pustule in one case [12].

Bone pain and dermatologic manifestations are the most troublesome SAPHO syndrome symptoms [13]. Bony lesions manifest as severe, recurrent, debilitating pain and tenderness. These symptoms can be more severe at night, adversely affect general well-being and can have a major impact on the entire family. Cutaneous manifestations include palmoplantar pustulosis (PPP), severe forms of acne (acne fulminans or conglobrata, hidradenitis suppurativa) and various forms of psoriasis, especially pustular psoriasis [14].

Because of misdiagnosis or lack of diagnosis, patients with SAPHO syndrome often receive long-term antibiotic therapy combined with surgical procedures, such as saucerisation, decortication, or partial resection of affected bones. However, as SAPHO syndrome etiology and pathophysiology are unknown, these treatment options are complex, uncomfortable, associated with multiple side effects [13,15] and ineffective in curing the disease [16-18]. Pain in SAPHO syndrome can be severe and last for several 
years; therefore early diagnosis is of great importance in order to avoid unnecessary procedures and promptly apply effective treatments.

To our knowledge few studies in the orthopaedic literature discuss osteitis or osteomyelitis in SAPHO syndrome [18-21]. In this report we describe the clinical, radiographic, and histological findings in five SAPHO syndrome patients. This is an attempt to increase awareness about SAPHO syndrome among Orthopaedic surgeons, so that they recognize it early when they see it. Prompt SAPHO syndrome recognition, followed by appropriate therapy can be remarkably effective, so that ineffective, unnecessary surgical or antibiotic therapies can be avoided.

\section{MATERIALS AND METHODOLOGY}

We present data from five patients ( 3 women, 2 men), ages 27 to 44 (median 33.6) years, who were referred to the Orthopaedic Department outpatient clinic for evaluation of skeletal pain of the humerus, clavicle, sacro-pelvic joints, and distal radius. Data collection and publication was approved by the Institution Ethics Committee. Clinical and radiological evaluation, including X-Rays, CT or MRI scans, and bone scans revealed osteitis and/or hyperostosis in all cases. No patient had skin lesions on initial evaluation, but three of them developed cutaneous manifestations during the assessment and treatment period. Bone biopsy was done in two of five cases.

Before starting treatment, the diagnosis of SAPHO syndrome was established based on the diagnostic criteria proposed by Benhamou et al. [22]. Treatment included non steroid anti-inflammatory medication (lornoxicam) and antibiotics (Clindamycin). Demographic, clinical presentation, treatment and outcome data are summarized in Table $\mathbf{1 .}$

\section{DESCRIPTION OF CASES}

\section{Case 1}

A 44-year-old woman suffered from recurrent right mandibular pain for 6 years. During these six years she underwent extensive diagnostic workup, including a negative open mandible biopsy. Due to worsening pain, she had biphosphonate therapy for a year, and underwent local excision of the right mandible lesion twice. After the $2^{\text {nd }}$ local excision, she was pain-free for 10 days, but then the pain returned. Eighteen months after her $2^{\text {nd }}$ mandible resection, she was referred to our orthopaedic outpatient clinic, for evaluation of left femur pain. Laboratory workup included ESR, CRP and CBC and was normal. Femur XRays showed one osteosclerotic lesion with cortical thickening and periosteal new bone formation (Fig. 1). Technetium $^{99}$ scan showed multiple locations of active uptake, including the right mandible, anterior chest wall, left pubic bone and left femur.

She underwent open left femur biopsy and surgical debridement. Biopsy and cultures were negative for malignancy or infection. As she fulfilled the Benhamou et al. [22] diagnostic criteria (Table 2), the SAPHO syndrome diagnosis was established. Treatment included oral Clindamycin 400mg 3 times a day and Lornoxicam $8 \mathrm{mg}$ twice a day for 3 months. Response to treatment was remarkably rapid: ten days after therapy started, her pain resolved. On her last follow-up visit, the patient was painfree, 18 months after treatment started. Follow-up X-Rays of

Table 1. Demographic, History, Presentation, Treatment and Outcome Data

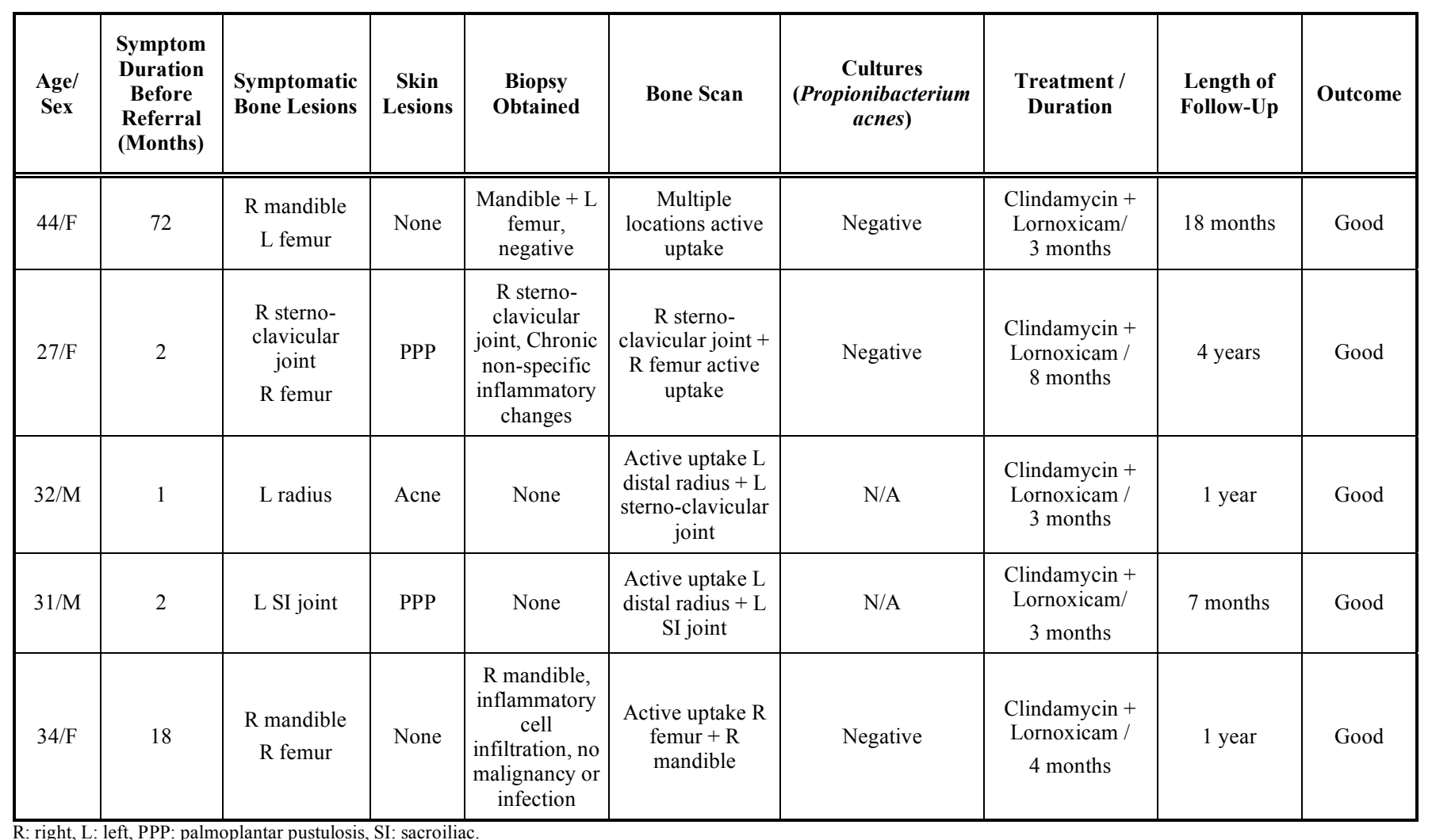


the left femur one year later showed that osteosclerosis and hypertrophic osteitis had improved significantly (Fig. 2).

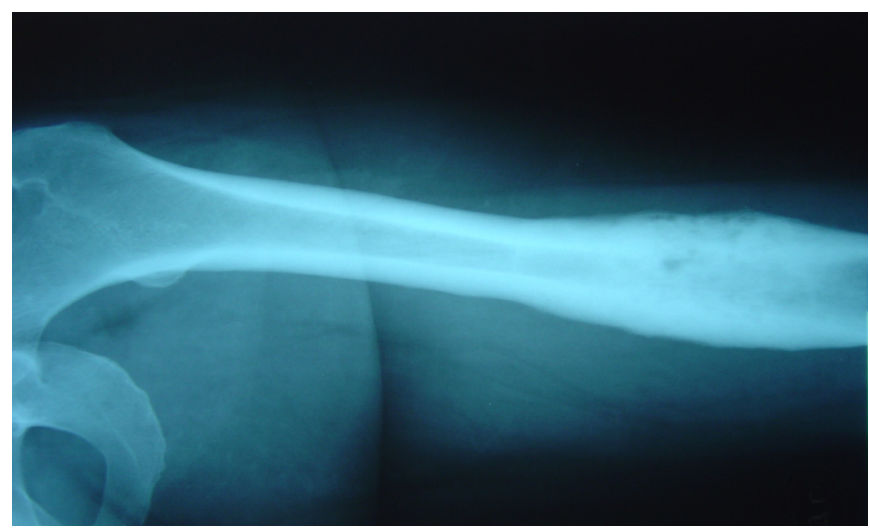

Fig. (1). Left femur X-Rays in case 1 show typical SAPHO osteosclerosis and hypertrophic osteitis.

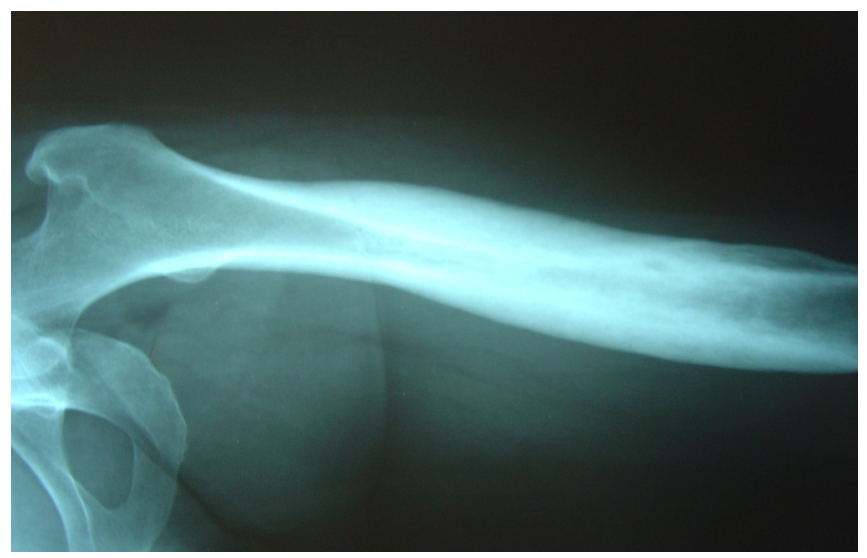

Fig. (2). Follow-up left femur X-Ray one year later: osteosclerosis and hypertrophic osteitis have improved significantly after treatment (case 1).

\section{Case 2}

A 27-year-old woman came to the orthopaedic outpatient clinic for evaluation of localized swelling and tenderness over the right sterno-clavicular joint (Fig. 3). There were no signs of infection, and laboratory workup was unremarkable. MRI demonstrated right sterno-clavicular joint hyperostosis changes and bone marrow oedema. Bone scan showed right sterno-clavicular joint and right femur active uptake. X-Rays of the asymptomatic right femur showed hyperostosis in the diaphysis.

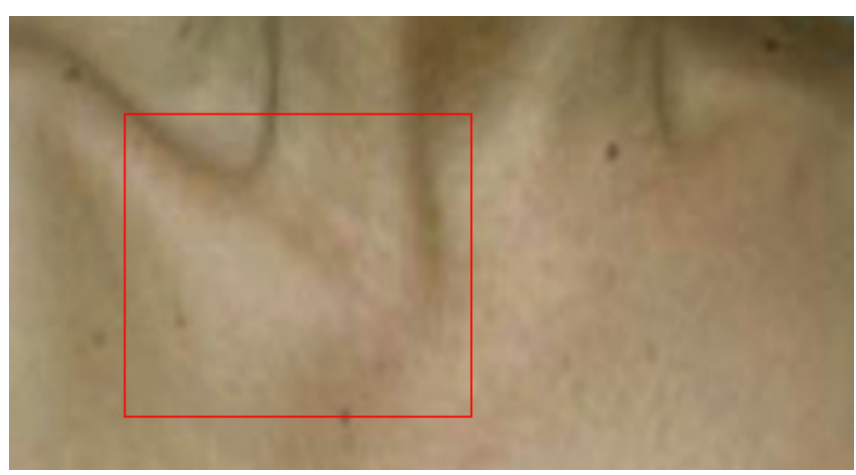

Fig. (3). Right sterno-clavicular joint edema in a 27 year old female (case 2).

An open sterno-clavicular joint biopsy was obtained; pathology examination revealed chronic, non-specific inflammatory changes, but all cultures were negative. She was discharged home on Lornoxicam $8 \mathrm{mg}$ p.o. twice a day, but episodes of swelling and pain persisted.

Six months later she returned for re-evaluation, because she developed PPP in her right foot. At that time diagnosis of SAPHO syndrome was established based on the Benhamou et al. criteria (Table 3). Treatment included oral clindamycin $400 \mathrm{mg}$ three times a day, lornoxicam $8 \mathrm{mg}$ twice/day, and local skin therapy with topical corticosteroids (CSs) and psoralen-ultraviolet A (PUVA). Symptoms improved significantly within 3 months after treatment started. After continuing treatment for eight months, right sterno-clavicular joint swelling and tenderness had disappeared, and treatment stopped. The patient remained symptom-free on her last follow-up visit 4 years later.

\section{Case 3}

A 32-year-old man was admitted to the Medicine floor for evaluation of fever of unknown origin, and had orthopaedic surgery consultation for pain at the left distal radius. There were no signs of local infection, and laboratory evaluation was unremarkable, except for moderately elevated ESR $\left(35 \mathrm{~mm} / 1^{\text {st }}\right.$ hour - normal is $<20 \mathrm{~mm} / 1^{\text {st }}$ hour). X-Rays revealed osteitis (osteosclerosis with homogenous fibrillary pattern) of the left distal radius (Fig. 4), and Technetium ${ }^{99}$ bone scan revealed active left distal radius and left sternoclavicular joint uptake. Symptoms improved after NSAID therapy started, and the patient went home one week later.

Two months later, the patient developed right foot acne and returned for re-evaluation. SAPHO syndrome was

Table 2. Diagnostic Criteria Proposed by Benhamou for SAPHO Syndrome Diagnosis [22]

\begin{tabular}{|l|l|}
\hline \multicolumn{1}{|c|}{ Inclusion Criteria } & Exclusion Criteria \\
\hline \hline Skin manifestations of severe acne & Septic osteomyelitis \\
\hline Skin manifestations of palmoplantar pustulosis & Infectious chest wall arthritis \\
\hline Hyperostosis with or without dermatosis & Infectious palmoplantar pustulosis \\
\hline $\begin{array}{l}\text { Chronic recurrent multifocal osteomyelitis involving axial or peripheral skeleton, with or } \\
\text { without dermatosis }\end{array}$ & Palmoplantar keratodermia \\
\hline & Diffuse idiopathic skeletal hyperostosis \\
\hline & Osteoarticular manifestations of retinoid therapy \\
\hline
\end{tabular}


Table 3. Patient Presentation - Inclusion Criteria According to Benhamou Present in Each Case

\begin{tabular}{|c|c|c|c|c|}
\hline \multirow{2}{*}{ Case } & \multicolumn{4}{|c|}{ Inclusion Features - Any one of these 4 Items is Sufficient to Diagnose the Syndrome, in the Absence of an Exclusion Feature } \\
\cline { 2 - 5 } & Skin Manifestations of Severe Acne & $\begin{array}{c}\text { Skin Manifestations } \\
\text { of PPP }\end{array}$ & $\begin{array}{c}\text { Hyperostosis with or } \\
\text { without Dermatosis }\end{array}$ & $\begin{array}{c}\text { CRMO Involving Axial or Peripheral } \\
\text { Skeleton, with or without Dermatosis }\end{array}$ \\
\hline \hline 1 & No & No & Yes & Yes \\
\hline 2 & No & Yes & Yes & Yes \\
\hline 3 & Yes & No & Yes & Yes \\
\hline 4 & No & Yes & Yes & Yes \\
\hline 5 & No & No & & Yes \\
\hline
\end{tabular}

PPP $=$ Palmoplantar pustulosis.

$\mathrm{CRMO}=$ Chronic Recurrent Multifocal Osteomyelitis

diagnosed, based on the Benhamou criteria (Tables 2 and 3). Treatment with oral Clindamycin $400 \mathrm{mg} 3$ times a day and Lornoxicam $8 \mathrm{mg}$ twice a day started promptly and continued for 3 months. One year after finishing treatment, the patient was pain-free, without any clinical or laboratory abnormalities.

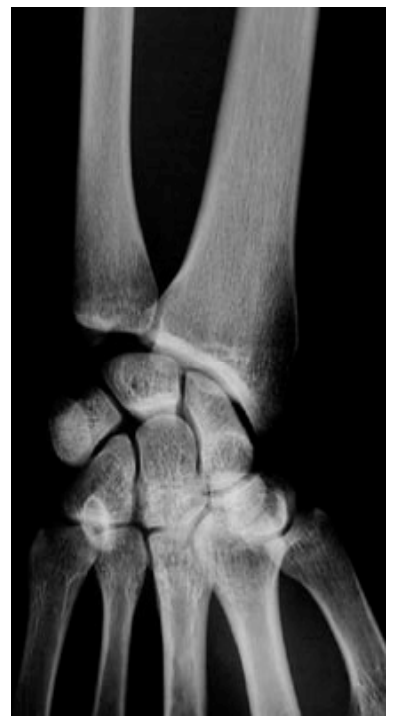

Fig. (4). Left distal radius sclerosis in a 32 year-old male (case 3).

\section{Case 4}

A 31-year-old man was referred to the Orthopaedic outpatient clinic for evaluation of left sacroiliac (SI) joint pain. Physical examination revealed left hand PPP. Laboratory workup was normal, but X-Rays revealed left SI joint osteitis (osteosclerosis with a homogenous fibrillary pattern). Bone scan showed active uptake of the left distal radius and left SI joint.

He was treated for SAPHO with oral Clindamycin 400 $\mathrm{mg} 3$ times a day and Lornoxicam $8 \mathrm{mg}$ twice a day for 3 months. At his last follow-up visit, four months after finishing his treatment course, he remained pain-free and skin lesions have resolved.

\section{Case 5}

A 34-year-old woman was evaluated at an outside hospital for right mandible pain lasting several weeks. Laboratory workup (CBC, electrolytes) was unremarkable. $\mathrm{X}$-Rays revealed diffuse right mandible cancellous bone sclerosis with osteolytic lesions and extensive periosteal reaction (Fig. 5). A mandible biopsy revealed infiltration by inflammatory cells, but no infection or malignancy. She started treatment with oral acetaminophen and NSAIDs, but symptoms persisted.

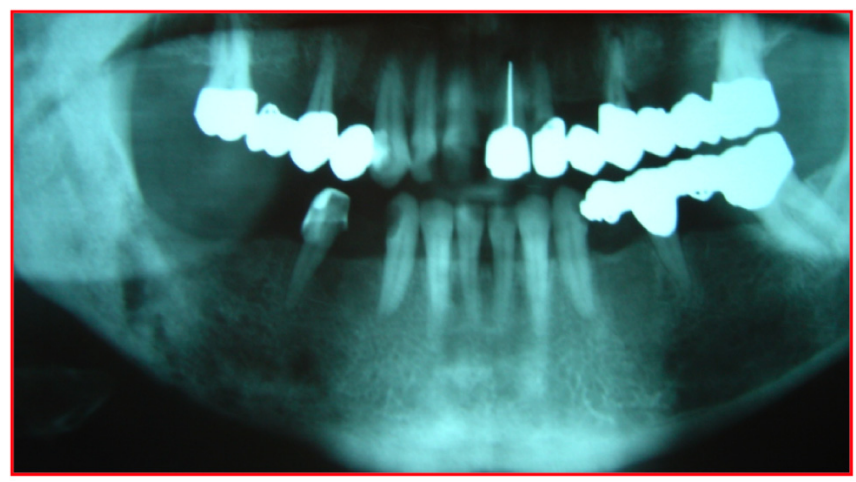

Fig. (5). Osteolytic mandible lesions in patient 5.

Approximately one year later, she came to our orthopaedic outpatient clinic for evaluation of right femur pain. There were no signs of local infection, and laboratory workup was unremarkable. X-Rays revealed right femur osteitis (osteosclerosis with a homogenous fibrillary pattern). Technetium ${ }^{99}$ bone scan showed active right femur and right mandible uptake. SAPHO syndrome was diagnosed, based on the Benhamou criteria (Table 2). Treatment consisted of oral Clindamycin $400 \mathrm{mg} 3$ times a day and Lornoxicam 8 mg twice a day for four months. One year after completing her treatment course, the patient was pain-free and radiologic findings had improved.

\section{DISCUSSION}

\section{Clinical Presentation}

SAPHO syndrome is a complex disorder, characterized by peculiar combinations of bone lesions and dermatologic manifestations. Patients typically present with musculoskeletal complaints, usually of the anterior chest wall, synovial articulations and synchondroses. In young and middle-aged adults the disease is more common in the sterno-clavicular region (65-90\% of patients), but can also affect the spine $(33 \%)$, pelvis $(13-52 \%)$ and long bones $(30 \%)$ [5], whereas the ilium and mandible are involved in less than $10 \%$ of cases [3]. Various articular manifestations, often due to osteitis extending to adjacent articular 
structures, especially in the sacroiliac and sterno-clavicular joints, may accompany the skin and bone lesions.

Skin involvement includes PPP, severe cystic acne and pustular psoriasis. Skin lesions may precede, occur concurrently or appear after onset of osteoarticular manifestations [3], but may be initially absent in $1 / 3$ of patients [23]; consequently, absence of skin lesions does not exclude SAPHO syndrome [24]. The interval between onset of skin manifestations and osteoarticular lesions is generally less than 2 years, but intervals as long as 20 and 38 years have been reported [3, 25-28].

\section{Diagnosis}

Diagnosis of SAPHO syndrome is based on exclusion of infectious arthritis or osteomyelitis, and the presence of at least one of four diagnostic criteria (Table 2) proposed by Benhamou [22]. Consequently, SAPHO syndrome diagnosis is difficult in patients with a solitary symptomatic bone lesion, because a solitary skeletal lesion can be misdiagnosed as suppurative osteomyelitis, a condition with similar clinical and pathologic findings [14]. Conservative treatment, consisting of antimicrobial therapy and NSAIDs, is generally effective in SAPHO syndrome, without a need for invasive treatments [3,13,29-33].

In our case series, bony lesions preceded skin manifestations in two cases, bony and skin lesions coexisted in one, whereas two patients had no skin involvement. Initial symptoms involved the sterno-clavicular region in 1 case, long bones in 3, mandible in 2 and SI joint in 1 case. The differential diagnosis includes tumors, infectious arthritis, bacterial osteomyelitis, and Paget's disease.

Laboratory findings are usually of little value, and include mild, non-specific elevation of various inflammatory indices. CRP and ESR are normal or slightly elevated during exacerbations, but white cell count is usually normal. In adults with SAPHO syndrome, prevalence of the HLA-B27 antigen is high, varying between $13 \%$ and $30 \%[2,3]$. Our patients had normal laboratory findings, except for one patient with slightly elevated ESR. HLA-B27 testing was not done in any patient.

Radiologic findings in SAPHO syndrome include osteolysis (Fig. 5), osteitis (Fig. 1), hyperostosis, and osteosclerosis (Figs. 1, 2) [19]. Osteitis usually presents as osteosclerosis with homogenous fibrillary pattern [3]. Hyperostosis, is highly characteristic of SAPHO, and is characterized by chronic periosteal reaction and cortical thickening, resulting in bone hypertrophy. Joint erosions involving adjacent articulations are frequently seen as result of primary arthritis or extension of adjacent osteitis. CT and MRI are helpful in locating the lesions and providing information on adjacent soft tissues, but cannot distinguish between SAPHO lesions, osteomyelitis and malignancy $[34,35]$. Bone scintigraphy is important in diagnosing SAPHO syndrome, particularly for detecting early bone involvement [36-38]. Lesions appearing in typical sites are important for correct diagnosis. Bone biopsy is often used in an attempt to establish a diagnosis, especially in cases with extra-axial bone lesions, which are particularly prone to radiologic misdiagnosis. Bone lesion histopathology is variable, with early lesions characterized by the presence of polymorphonuclear infiltrate. An intermediate phase is characterized by chronic inflammation (primarily mononuclear cells), whereas lesions with markedly enlarged and sclerotic bone trabeculae and prominent marrow fibrosis are seen in late phases [39]. Propionibacterium acnes, a skin saprophyte, has been isolated from cutaneous lesions with severe acne and from articular and osseous lesions associated with pustulosis. However, most biopsies of involved areas demonstrate nonspecific inflammatory infiltrate [4], and therefore cannot confirm the diagnosis. In our series, 3 of 5 patients underwent open lesion biopsy, but all biopsies were negative for malignancy, and all cultures were negative for bacteria.

As SAPHO syndrome pathogenesis remains unknown, two hypotheses have been proposed. According to the first hypothesis, bone lesions are caused by a low virulence pathogen transmitted via a blood-borne route. Alternatively an autoimmune response may be triggered by a bacterial or viral pathogen [40]. The second hypothesis suggests a link with sero-negative spondylo-arthropathies, based on the high frequency of axial involvement (sacroiliitis and spinal lesions), asymmetric paravertebral ossification (indistinguishable from ossification encountered in psoriatic spondyloarthropathy) and the possible association with psoriasis and inflammatory bowel (Crohn's and ulcerative colitis) diseases.

\section{Treatment}

Treatment options for SAPHO include NSAIDs, antirheumatic drugs, such as colchicine, corticosteroids and biphosphonates, and disease-modifying agents, such as methotrexate, sulfasalazine and infliximab [29]. Biphosphonates, which act by inhibiting bone resorption and turnover $[41,42]$, are often used as disease modifiers $[15,42,43]$ and anti-inflammatory agents [44,45]. Antimicrobial therapies are a reasonable choice, since bacteria, such as $\mathrm{P}$ acnes [46] and Staph. Aureus [12] have been isolated in specimens from SAPHO patients, and have been implicated in SAPHO pathogenesis. Azithromycin, doxycycline, sulfamethoxazole/ trimetoprim and clindamycin use has been reported in SAPHO $[12,46]$. Local treatments, including local corticosteroid injections have also been tried. Dermatologic treatments include topical corticosteroids, tetracycline, other antimicrobial agents, psoralen-ultraviolet A (PUVA) and retinoinds [3]. Among all treatment options listed above, NSAIDS are generally considered as first-line treatment in SAPHO, whereas disease-modifying agents are only indicated when symptoms persist for at least four weeks despite adequate NSAID therapy.

In previous reports, antimicrobials were only given to a minority of cases [3]. Furthermore, a recent study evaluating the role of antibiotic therapy in SAPHO concluded that antibiotic therapy is effective, but SAPHO tends to relapse when antibiotics are discontinued after 16 weeks of treatment [46]. However, our limited experience on five cases suggests that antimicrobial therapy against P. Acnes could be considered first-line therapy, and might help avoid symptom recurrence. We believe that surgery is only indicated when SAPHO-induced changes adversely affect bone mechanics. However, surgery, such as prophylactic intra-medullary nailing, is also a reasonable consideration when bone destruction increases the risk of pathologic 
fractures. In our case series, only patient \#1 had surgery, but this operation was done in an outside hospital, before SAPHO syndrome was diagnosed in our clinic.

\section{Outcome}

In our series, after SAPHO syndrome diagnosis was established, all patients promptly received treatment with oral NSAIDs and oral Clindamycin, while patients who developed dermatological manifestations also received topical CSs, and psoralen-ultraviolet A (PUVA). Although biphosphonates were not used, our results were very satisfactory: All patients experienced long-lasting clinical and radiologic improvement after 3-8 months of therapy, and relief persisted during long-term (4 months to 4 years, median 1 year) follow-up.

\section{CONCLUSION}

"SAPHO syndrome" is a constellation of musculoskeletal disorders associated with skin conditions. Osteitis is the main skeletal lesion, whereas PPP and acne are important skin lesions. Orthopaedic surgeons should be aware of SAPHO syndrome, and maintain a high level of suspicion, especially when evaluating patients with persistent nonspecific symptoms involving the bone, joints, and/or skin. Prompt SAPHO syndrome recognition, followed by appropriate NSAID and antibiotic therapy will help avoid unnecessary examinations, biopsies and invasive treatments, and may result in long-lasting symptom relief.

\section{AUTHOR CONTRIBUTIONS}

Matzaroglou Charis evaluated, treated and did follow-up on all patients.

Velissaris Dimitrios collected data and edited the manuscript.

Karageorgos Athanasios participated in patient care and collected data.

Marangos Markos participated in patient care and directed antibiotic therapy.

Panagiotopoulos Elias supervised patient care and edited manuscript.

Karanikolas Menelaos wrote, edited and submitted the manuscript.

\section{CONFLICT OF INTEREST}

This project was supported solely from Department funds, without any external financial support. Therefore, we do not have any conflict of interest to report.

\section{ABBREVIATIONS}

$$
\begin{array}{ll}
\mathrm{CBC} & =\text { Complete Blood Count } \\
\mathrm{CRMO} & =\text { Chronic Recurrent Multifocal Osteomyelitis } \\
\mathrm{CRP} & =\text { C-Reactive Protein } \\
\mathrm{CSs} & =\text { Corticosteroids } \\
\mathrm{CT} & =\text { Computerized Tomography } \\
\mathrm{ESR} & =\text { Erythrocyte Sedimentation Rate } \\
\text { MRI } & =\text { Magnetic Resonance Imaging } \\
\text { NSAIDs } & =\text { Non-Steroidal Anti-Inflammatory Drugs }
\end{array}
$$

PPP $=$ Palmo-Plantar Pustulosis

SAPHO = Synovitis, Acne, Pustulosis, Hyperostosis and Osteitis

SI $=$ Sacroiliac joint

\section{REFERENCES}

[1] Suei Y, Taguchi A, Tanimoto K. Diagnostic points and possible origin of osteomyelitis in synovitis, acne, pustulosis, hyperostosis and osteitis (SAPHO) syndrome: A radiographic study of 77 mandibular osteomyelitis cases. Rheumatology (Oxford) 2003; 42: 1398-403.

[2] Chamot AM, Benhamou CL, Kahn MF, Beraneck L, Kaplan G, Prost A. Acne-pustulosis-hyperostosis-osteitis syndrome. Results of a national survey 85 cases. Rev Rhum Mal Osteoartic 1987; 54: 187-96.

[3] Hayem G, Bouchaud-Chabot A, Benali K, et al. SAPHO syndrome: a long-term follow-up study of 120 cases. Semin Arthritis Rheum 1999; 29: 159-71.

[4] Boutin RD, Resnick D. The SAPHO syndrome: An evolving concept for unifying several idiopathic disorders of bone and skin. AJR Am J Roentgenol 1998; 170: 585-91.

[5] Earwaker JW, Cotten A. SAPHO: Syndrome or concept? Imaging findings. Skeletal Radiol 2003; 32: 311-27.

[6] Chamot AM, Kahn MF. SAPHO syndrome. Z Rheumatol 1994; 53 : 234-42.

[7] Ballara SC, Siraj QH, Maini RN, Venables PJ. Sustained response to doxycycline therapy in two patients with SAPHO syndrome. Arthritis Rheum 1999; 42: 819-21.

[8] Jacobsson S. Diffuse sclerosing osteomyelitis of the mandible. Int J Oral Surg 1984; 13: 363-85.

[9] Kotilainen P, Merilahti-Palo R, Lehtonen OP, et al. Propionibacterium acnes isolated from sternal osteitis in a patient with SAPHO syndrome. J Rheumatol 1996; 23: 1302-4.

[10] Gerster JC, Lagier R, Livio JJ. Propionibacterium acnes in a spondylitis with palmoplantar pustulosis. Ann Rheum Dis 1990; 49: 337-338.

[11] Edlund E, Johnsson U, Lidgren L, et al. Palmoplantar pustulosis and sternocostoclavicular arthro-osteitis. Ann Rheum Dis 1988; 47: 809-15.

[12] Rozin AP, Nahir AM. Is SAPHO syndrome a target for antibiotic therapy? Clin Rheumatol 2007; 26: 817-20.

[13] Marshall H, Bromilow J, Thomas AL, Arden NK. Pamidronate: A novel treatment for the SAPHO syndrome? Rheumatology (Oxford) 2002; 41: 231-3.

[14] Kahn MF, Khan MA. The SAPHO syndrome. Baillieres Clin Rheumatol 1994; 8: 333-62.

[15] Guignard S, Job-Deslandre C, Sayag-Boukris V, Kahan A. Pamidronate treatment in SAPHO syndrome. Joint Bone Spine 2002; 69: 392-6

[16] Eyrich GK, Harder C, Sailer HF, Langenegger T, Bruder E, Michel BA: Primary chronic osteomyelitis associated with synovitis, acne, pustulosis, hyperostosis and osteitis (SAPHO syndrome). J Oral Pathol Med 1999; 28: 456-64.

[17] Suei Y, Taguchi A, Tanimoto K, Yamada T, Otani K, Fukuda T. Case report. synovitis, acne, pustulosis, hyperostosis and osteitis (SAPHO) syndrome. Dentomaxillofac Radiol 1996; 25: 287-91.

[18] Jurik AG, Moller BN. Chronic sclerosing osteomyelitis of the clavicle. A manifestation of chronic recurrent multifocal osteomyelitis. Arch Orthop Trauma Surg 1987; 106: 144-51.

[19] Franz T, Lehmann T, Eggli S. Case reports: Aseptic femoral osteitis and sternocostal hyperostosis from SAPHO syndrome. Clin Orthop Relat Res 2005; 438: 277-81.

[20] Roldan JC, Terheyden H, Dunsche A, Kampen WU, Schroeder JO. Acne with chronic recurrent multifocal osteomyelitis involving the mandible as part of the SAPHO syndrome: Case report. Br J Oral Maxillofac Surg 2001; 39: 141-44.

[21] Rutten HP, van Langelaan EJ. The SAPHO syndrome--a report of 2 patients. Acta Orthop Scand 2002; 73: 590-593.

[22] Benhamou CL, Enjolras O, Delrieu F, Prier A, Camus JP, Amor B. Pseudoseptic arthritis and bacterid of Andrews. Rev Rhum Mal Osteoartic 1984; 51: 229-31.

[23] DiMeco F, Clatterbuck RE, Li KW, McCarthy EF, Olivi A. Synovitis, acne, pustulosis, hyperostosis, and osteitis syndrome 
presenting as a primary calvarial lesion. Case report and review of the literature. J Neurosurg 2000; 93: 693-97.

[24] Benhamou CL, Chamot AM, Kahn MF. Synovitis-acne-pustulosis hyperostosis-osteomyelitis syndrome (SAPHO). A new syndrome among the spondyloarthropathies? Clin Exp Rheumatol 1988; 6: 109-12.

[25] Kahn MF, Bouvier M, Palazzo E, Tebib JG, Colson F. Sternoclavicular pustulotic osteitis (SAPHO). 20-year interval between skin and bone lesions. J Rheumatol 1991; 18: 1104-8.

[26] Sonozaki H, Mitsui H, Miyanaga Y, et al. Clinical features of 53 cases with pustulotic arthro-osteitis. Ann Rheum Dis 1981; 40: 547-53.

[27] Van DS, Barraclough D, McColl G, Wicks I. SAPHO: Rare or just not recognized? Semin Arthritis Rheum 2000; 30: 70-77.

[28] Davies AM, Marino AJ, Evans N, Grimer RJ, Deshmukh N, Mangham DC. SAPHO syndrome: 20-year follow-up. Skeletal Radiol 1999; 28: 159-62.

[29] Olivieri I, Padula A, Ciancio G, Salvarani C, Niccoli L, Cantini F. Successful treatment of SAPHO syndrome with infliximab: Report of two cases. Ann Rheum Dis 2002; 61: 375-6.

[30] Beretta-Piccoli BC, Sauvain MJ, Gal I, et al. Synovitis, acne, pustulosis, hyperostosis, osteitis (SAPHO) syndrome in childhood: A report of ten cases and review of the literature. Eur J Pediatr 2000; 159: 594-601.

[31] Yoshii $\mathrm{T}$, Nishimura $\mathrm{H}$, Yoshikawa $\mathrm{T}$, et al. Therapeutic possibilities of long-term roxithromycin treatment for chronic diffuse sclerosing osteomyelitis of the mandible. J Antimicrob Chemother 2001; 47: 631-7.

[32] Montonen M, Kalso E, Pylkkaren L, Lindstrorm BM, Lindqvist C. Disodium clodronate in the treatment of diffuse sclerosing osteomyelitis (DSO) of the mandible. Int J Oral Maxillofac Surg 2001; 30: 313-7.

[33] Soubrier M, Dubost JJ, Ristori JM, Sauvezie B, Bussiere JL. Pamidronate in the treatment of diffuse sclerosing osteomyelitis of the mandible. Oral Surg Oral Med Oral Pathol Oral Radiol Endod 2001; $92: 637-40$
[34] Jurik AG, Egund N. MRI in chronic recurrent multifocal osteomyelitis. Skeletal Radiol 1997; 26: 230-8.

[35] Sundaram M, McDonald D, Engel E, Rotman M, Siegfried EC. Chronic recurrent multifocal osteomyelitis: An evolving clinical and radiological spectrum. Skeletal Radiol 1996; 25: 333-36.

[36] Dihlmann W, Dihlmann SW, Hering L. Acquired hyperostosis syndrome--AHYS--(sternocostoclavicular hyperostosis, pustulotic arthro-osteitis, SAPHO-syndrome): Bone scintigraphy of the anterior chest wall. Clin Rheumatol 1997; 16: 13-24.

[37] Otsuka N, Fukunaga M, Sone T, et al. Usefulness of bone imaging in diagnosis of sternocostoclavicular hyperostosis. Clin Nucl Med 1986; 11: 651-2.

[38] Rosenthall L, Burke DL. A radionuclide and radiographic diagnosis of sternocostoclavicular hyperostosis. Clin Nucl Med 1986; 11: $322-4$.

[39] Reith JD, Bauer TW, Schils JP. Osseous manifestations of SAPHO (synovitis, acne, pustulosis, hyperostosis, osteitis) syndrome. Am J Surg Pathol 1996; 20: 1368-77.

[40] Schwartz BD. Infectious agents, immunity, and rheumatic diseases. Arthritis Rheum 1990; 33: 457-65.

[41] Allgrove J. Biphosphonates. Arch Dis Child 1997; 76: 73-75.

[42] Astrom E, Soderhall S. Beneficial effect of long term intravenous bisphosphonate treatment of osteogenesis imperfecta. Arch Dis Child 2002; 86: 356-364.

[43] Amital H, Applbaum YH, Aamar S, Daniel N, Rubinow A. SAPHO syndrome treated with pamidronate: An open-label study of 10 patients. Rheumatology (Oxford) 2004; 43: 658-61.

[44] Maksymowych WP. Bisphosphonates for arthritis--a confusing rationale. J Rheumatol 2003; 30: 430-4.

[45] Pennanen N, Lapinjoki S, Urtti A, Monkkonen J. Effect of liposomal and free bisphosphonates on the IL- 1 beta, IL- 6 and TNF alpha secretion from RAW 264 cells in vitro. Pharm Res 1995; 12: 916-22.

[46] Assmann G, Kueck O, Kirchhoff T, et al. Efficacy of antibiotic therapy for SAPHO syndrome is lost after its discontinuation: Interventional study. Arthritis Res Ther 2009; 11: R140.

(C) Matzaroglou et al.; Licensee Bentham Open.

This is an open access article licensed under the terms of the Creative Commons Attribution Non-Commercial License (http://creativecommons.org/licenses/by-nc/ $3.0 /$ ) which permits unrestricted, non-commercial use, distribution and reproduction in any medium, provided the work is properly cited. 